\title{
A New Diagnostic Scoring for Discrimination of Tuberculous and Bacterial Meningitis on the Basis of Clinical and Laboratory Findings
}

\author{
Yasemin Ersoy $^{\mathrm{a}}$ Funda Yetkin ${ }^{\mathrm{a}} \quad$ Mehmet Refik Bayraktar $^{\mathrm{b}}$ Yuksel Ersoy $^{\mathrm{c}}$ \\ Saim Yologlud
}

Departments of ${ }^{\mathrm{a}}$ Infectious Diseases and Clinical Microbiology, ${ }^{\mathrm{b}}$ Medical Microbiology, ${ }^{\mathrm{c}}$ Physical Medicine and Rehabilitation and ${ }^{\mathrm{d}}$ Biostatistics, Inonu University Faculty of Medicine, Malatya, Turkey

\section{Key Words}

Bacterial meningitis $\cdot \mathrm{C}$-reactive protein $\cdot$ Diagnostics .

Tuberculosis

\begin{abstract}
Objectives: The aim of this study was to develop a new diagnostic index (DI) on the basis of clinical and laboratory findings including serum C-reactive protein (CRP) for tuberculous meningitis (TM) and bacterial meningitis (BM). Subjects and Methods: During a 7-year period, 96 adult patients with meningitis ( 30 with TM and 66 with BM) were studied retrospectively. Multivariate logistic regression analysis was performed to investigate the diagnostic value of clinical and laboratory parameters as independent predictors on discrimination of tuberculous from BM patients. Results: Six features predictive for diagnosis including age, CSF leukocyte count, PML dominance, length of illness, serum CRP level and blood WBC count were used. The DI model developed from these features had very high sensitivity and specificity rates of 100.0 and $95.4 \%$, respectively. The sensitivity and specificity rates were 97.4 and 100\%, respectively, in microbiologically proven cases. Conclusion: Our results suggested that this new DI which consists of simple clinical and laboratory parameters had the power to discriminate adult pa-
\end{abstract}

tients with documented tuberculous and BM (excluding Brucella meningitis). It should, however, be tested in prospective studies.

Copyright $\odot 2011$ S. Karger AG, Basel

\section{Introduction}

Meningitis is a critical disease that needs rapid diagnosis and initiation of appropriate early treatment, otherwise it could lead to permanent disabilities or death, since there is a high rate of mortality for meningitis [1-3]. Laboratory tests usually lack the power to discriminate between bacterial meningitis (BM) and non-BM $[3,4]$. The etiology of meningitis is usually bacterial or viral. However, tuberculous meningitis (TM) is still one of the most important types in developing countries [5] and, in 2009 , the incidence of tuberculosis in Turkey was reported as 29 per 100,000 population [6]. TM has been reported as the second or third most common form of extrapulmonary tuberculosis [7-9]. Differential diagnosis of tuberculous from BM is important for initial treatment strategies. Thwaites' diagnostic criteria was conducted for discrimination of bacterial and TM, including age, history of illness, white blood cell count, total cerebrospi-

\section{KARGER}

Fax +4161306 1234

E-Mail karger@karger.ch

www.karger.com
(C) 2011 S. Karger AG, Basel

$1011-7571 / 12 / 0213-0259 \$ 38.00 / 0$

Accessible online at:

www.karger.com/mpp
Dr. Yasemin Ersoy

Inonu University Faculty of Medicine, Turgut Ozal Medical Center

Department of Infectious Diseases and Clinical Microbiology

TR-44280 Malatya (Turkey)

Tel. +90 422341 1059, E-Mail dryasemin@ hotmail.com 
nal fluid (CSF) white cell count and the percent of neutrophils in CSF [10]. However, this scoring method does not include the important laboratory parameter of serum C-reactive protein (CRP) level. The CRP, an acute-phase reactant, is rapidly synthesized by the liver in most invasive bacterial infections as well as in many infections and inflammations. We thought that this easy and inexpensive method might increase the sensitivity and specificity of the diagnostic criteria. Therefore, the objective of the present study was to determine a new diagnostic index (DI) using both clinical and laboratory findings, including serum CRP level for tuberculous and BM in adult patients.

\section{Subjects and Methods}

This retrospective study was performed on adult patients hospitalized with meningitis at the Infectious Disease Unit in Turgut Ozal Medical Center, Inonu University Faculty of Medicine during the period of January 2000 to June 2007. Those patients admitted with clinical and laboratory findings of tuberculous and BM with positive lumbar puncture and CRP recording within the first $24 \mathrm{~h}$ were included in the study. Patients with infections other than meningitis were excluded from the study because an increase in serum CRP may be related to extrameningeal infections. Patients with viral meningitis and those with no values of CRP within the first $24 \mathrm{~h}$ were also excluded. Brucella meningitis patients were also excluded from the BM group because of the chronic clinical course and similar CSF findings to TM rather than BM. Viral meningitis cases were defined as patients with a pleocytosis in the CSF, the absence of any bacterial growth on culture of the CSF, benign and acute clinical course, and no etiologic agents other than viral infection [11]. Brucella meningitis was defined as those patients diagnosed with CSF culture positivity and pleocytosis in CSF with standard tube agglutination test $\geq 1: 160$. Clinical symptoms and signs of fever, headache, duration of illness, meningeal irritation signs, an altered level of consciousness, and neurological deficiencies were recorded. Laboratory tests from CSF (protein, glucose concentration and leukocyte counts) and blood (leukocyte counts, erythrocyte sedimentation rate, C-reactive protein) were obtained. All CSF samples were stained with Gram, India ink, Ehrlich-Ziehl-Neelsen and cultured on blood and chocolate agar and Lowenstein-Jensen media.

Patients were categorized into two subgroups according to the causative agents of tuberculous or BM. (1) TM: Mycobacterium tuberculosis isolated from CSF or clinical meningitis with negative Gram stain and sterile bacterial and fungal cultures plus one or more of the following: (a) cranial tomographic or cranial magnetic resonance image consistent with tuberculoma or hydrocephalus, (b) chest radiograph or chest CT consistent with miliary or active tuberculosis, and (c) good response to antituberculous treatment $[1,10]$. (2) BM: A pathogenic bacteria isolated from CSF or clinical signs and symptoms of meningitis with pleocytosis in CSF and blood culture yielding a bacteria or Gram stain of CSF demonstrated a bacteriologic agent $[10,11]$.
Data were obtained from the patients' hospital files and computer records. Serum CRP levels were estimated by nephelometric method. There was no HIV-positive patient.

Statistical Analysis

Clinical and laboratory parameters of those who fulfilled the diagnostic criteria for bacterial and TM were compared. Normality for continuous variables was determined by the KolmogorowSmirnov test. As the variables did not show normal distribution $(\mathrm{p}<0.05)$, data were expressed as the median \pm interquartile ranges (IR) for continuous variables and frequency (\%) for categorical variables. The differences of continuous variables between the groups were assessed using the Kruskal-Wallis test, while for categorical variables the $\chi^{2}$ test (or Fisher's exact test for small proportions) was preferred.

Logistic regression analysis with a stepwise forward variable selection procedure was performed to investigate the independent effects of the determined significant variables between the groups. The cut-off times of any non-categorical variable shown to have an independent effect on predicting the diagnosis of tuberculous/ $\mathrm{BM}$ were calculated. The final model by dichotomizing the variables and rounding the coefficients in the model were performed for determining the DI scores for each variable. The odds ratios (ORs), sensitivities, specificities, predictive values and likelihood ratios of cut-off times of total DI score were calculated; $p$ values $<0.05$ were considered significant. Statistical analyses were performed using the SPSS software version 16.0 (SPSS Inc., Chicago, Ill., USA).

\section{Results}

One hundred and forty-nine patients with meningitis were hospitalized for diagnosis and treatment. Ten patients whose serum CRP had not been obtained within $24 \mathrm{~h}$ after admission, 37 patients with viral meningitis and 6 Brucella meningitis patients were excluded. Ninety-six patients (30 TM and $66 \mathrm{BM}$ ) were included in the study. Patient characteristics, clinical, CSF and blood laboratory findings are shown in table 1.

In the BM group, Streptococcus pneumoniae $(\mathrm{n}=20)$, Neisseria meningitidis $(\mathrm{n}=6)$, Streptococcus pyogenes $(\mathrm{n}=3)$, Streptococcus spp. $(\mathrm{n}=2)$, Listeria monocytogenes $(\mathrm{n}=2)$, Staphylococcus spp. $(\mathrm{n}=4)$ and Pseudomonas aeruginosa $(\mathrm{n}=1)$ were isolated from the CSF culture. Culture positivity for BM was 57.6\% (38/66). The diagnosis was made on the basis of observation of any bacteriologic agents on the Gram stain of the CSF for 28 patients. Brucella meningitis was diagnosed by isolation of bacteria from CSF for 5 patients and standard tube agglutination test result $\geq 1: 160$ for one Brucella meningitis patient. In the TM group, 19 (63.3\%) patients were culture positive. However, 11 culture negative patients were diagnosed with radiological findings (6 with tuberculoma, 2 
Table 1. Univariate analyses comparing variables between patients with TM $(n=30)$ and BM $(n=66)$

\begin{tabular}{lccc}
\hline Variables & TM & BM & p \\
\hline Age, years & $30 \pm 27$ & $45 \pm 36$ & 0.026 \\
Gender, female/male & $20 / 10$ & $23 / 43$ & 0.003 \\
Fever & $26(86.7)$ & $64(97.0)$ & $>0.05$ \\
Headache & $29(96.7)$ & $66(100.0)$ & $>0.05$ \\
Loss of consciousness & $18(60.0)$ & $51(77.3)$ & $>0.05$ \\
Neurological deficits & $15(50.0)$ & $24(36.4)$ & $>0.05$ \\
Meningeal irritation signs & $23(76.7)$ & $52(78.8)$ & $>0.05$ \\
CSF leukocyte count, cells/ml & $120 \pm 220$ & $2,390 \pm 5,365$ & 0.0002 \\
CSF protein, mg/dl & $160 \pm 92.5$ & $150.5 \pm 159.8$ & $>0.05$ \\
CSF/blood glucose ratio & $0.23 \pm 0.19$ & $0.21 \pm 0.38$ & $>0.05$ \\
Blood WBC, $\times 10^{3} / \mathrm{ml}$ & $10.0 \pm 6.0$ & $18.0 \pm 8.8$ & 0.0008 \\
Serum CRP, mg/l & $12 \pm 18$ & $86 \pm 135$ & 0.0004 \\
Blood ESR, mm/h & $25 \pm 25$ & $64 \pm 67$ & 0.001 \\
Duration of illness, days & $7 \pm 18$ & $2 \pm 1$ & 0.0002 \\
Predominance of PML in CSF & $4(13.3)$ & $60(80.0)$ & 0.0009 \\
Culture positivity & $19(63.3)$ & $38(57.6)$ & $>0.05$ \\
\hline
\end{tabular}

Figures are medians and interquartile ranges or numbers with percentages in parentheses.

$\mathrm{CSF}=$ Cerebrospinal fluid; $\mathrm{PML}=$ polymorphonuclear leukocytes; $\mathrm{WBC}=$ white blood cells; $\mathrm{ESR}=$ erythrocyte sedimentation rate.

with hydrocephalus in cranial MR, and 2 with miliary lesions on chest $\mathrm{x}$-ray) as well as 1 patient with a good response to the antituberculous therapy.

Gender, fever, headache, loss of consciousness, neurological deficits, meningeal irritation signs, CSF protein, $\mathrm{CSF} /$ blood glucose ratio and ESR were excluded due to the nonsignificant results by univariate analysis (table 1).

Stepwise logistic regression analysis done to construct a diagnostic rule showed that six variables (age $\leq 56$ years, duration of illness $>4$ days, CSF leukocyte count $\leq 650$ cells $/ \mathrm{ml}$, blood $\mathrm{WBC} \leq 14 \times 10^{3} / \mathrm{ml}$, serum CRP $\leq 26$ $\mathrm{mg} / \mathrm{l}$ and predominance of PML in $\mathrm{CSF}<50 \%$ ) were independently associated with a diagnosis of TM. The formula for DI was derived from the final model by dichotomizing the continuous variables and rounding the coefficients in the model (table 2). The total DI was calculated for each patient according to the formula: DI score $=$ DI (age) + DI (blood white-cell count) + DI (history of illness) + DI (cerebrospinal fluid white-cell count) + DI (cerebrospinal fluid \% neutrophils) + DI (serum CRP).

The optimum cutoff for the total DI (by which to classify a patient as having TM or BM) was found by use of a ROC curve (fig. 1). The DI model developed from these features had very high sensitivity and specificity rates of 100.0 and $95.4 \%$, respectively. Therefore, the suggested

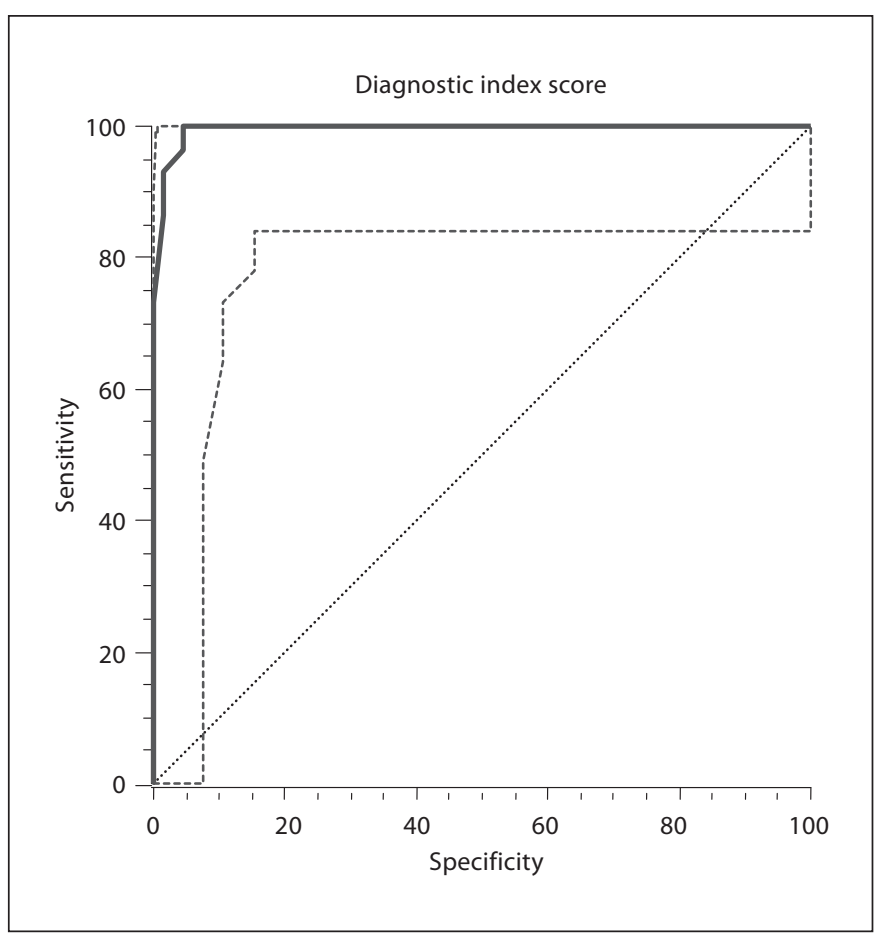

Fig. 1. ROC curve for DI scores derived from logistic regression model with high sensitivity and specificity rates. DI $>4=\mathrm{BM}$; $\mathrm{DI} \leq 4=\mathrm{TM}(\mathrm{AUC}=0.995 ; 95 \% \mathrm{CI}=0.953-0.996$; sensitivity $=$ $100 \%$; specificity $=95.4 \% ; \mathrm{p}=0.0001)$. 
Table 2. Weighted DI scores for dichotomized variables used for diagnosis

\begin{tabular}{lll}
\hline Variables & & DI points \\
\hline PMNL & $\geq 50 \%$ & 3 \\
& $<50 \%$ & 0 \\
Duration of illness & $\leq 4$ days & 0 \\
& $>4$ days & -3 \\
Blood WBC & $>14 \times 10^{3} / \mathrm{ml}$ & 2 \\
Serum CRP & $\leq 14 \times 10^{3} / \mathrm{ml}$ & 0 \\
& $>26 \mathrm{mg} / \mathrm{l}$ & 4 \\
Age & $\leq 26 \mathrm{mg} / \mathrm{l}$ & 0 \\
CSF leukocyte count & $>56$ years & 2 \\
& $\leq 56$ years & 0 \\
& $\leq 650$ cells $/ \mathrm{ml}$ & 9 \\
& $\leq 650$ cells $/ \mathrm{ml}$ & 0 \\
\hline
\end{tabular}

PMNL $=$ Polymorphonuclear leukocytes WBC $=$ white blood cells; CSF = cerebrospinal fluid.

Diagnostic rule: If the patient has a total DI score $\leq 4$ points, he/she has TM; if the patient has total DI score $>4$ points, he/she has BM.

diagnostic rule was that a total DI score of 4 or less indicated TM while a score of more than 4 indicated BM $(\mathrm{AUC}=0.995 ; 95 \% \mathrm{CI}=0.953-0.996$; sensitivity $=95.5 \%$; specificity $=100.0 \% ; \mathrm{p}=0.0001)$. The sensitivity and the specificity rates were $97.4 \%$ and $100 \%$, respectively, in microbiologically proven cases. The DI scores of six Brucella meningitis patients were between 0 and -2 points that were calculated with the resubstitution method.

\section{Discussion}

In this study, we developed a new DI score that included serum CRP level with very high sensitivity and specificity rates (95.4 and $100.0 \%$, respectively) for diagnosing adult TM patients. In 2002, Thwaites et al. [10] developed a DI for discrimination of bacterial and TM in a large series. They reported $97 \%$ sensitivity and $91 \%$ specificity by the resubstitution method. Their criteria included age, history of illness, white blood cell count, total cerebrospinal fluid (CSF) white cell count and the percent of neutrophils in CSF. In our new DI, we added serum CRP level because CRP usually is a helpful parameter for bacterial infections. Therefore, this new index may be called a 'Modified Thwaites' Index.

The definition of BM in our study for culture-negative patients was pleocytosis and a positive Gram stain.
Thwaites et al. [10] described the BM patient as culturepositive or recovering in 3 months without anti-tuberculous treatment and a low concentration of glucose in CSF ( $<50 \%$ of that in blood). However, this definition for BM may misclassify a few viral meningitis cases among BM patients.

Gram stain of CSF can certainly help to make a diagnosis of BM with a specificity approaching $100 \%[3,11]$. Also, low glucose level in CSF was evaluated if it was an independent parameter in our study.

Thwaites' diagnostic scoring was evaluated in a retrospective study by Sunbul et al. [12] who reported sensitivity and specificity rates of 95.8 and $71.6 \%$, respectively. However, in microbiologically proven patients, the sensitivity decreased to $91.7 \%$ and the specificity increased to $79.7 \%$. In our study, the new DI had a sensitivity and specificity in microbiologically proven cases of 97.7 and $100 \%$, respectively. Adding serum CRP to this useful technique improved the power of the diagnostic score for TM from BM.

Validation of the Thwaites' diagnostic algorithm was evaluated in a study by Torok et al. [13]. The logistic regression method reported good sensitivity as $99 \%$; however specificity was reported as $81 \%$ for differentiate adult TM patients. We recommend that our new DI be validated in prospective studies.

We did not include Brucella meningitis patients because the clinical course of Brucella meningitis is usually chronic and CSF findings can be very similar to TM. In addition, treatment of Brucella meningitis (selection of antibiotics and duration of treatment) is different from $\mathrm{BM}$. For these reasons, we thought that including these patients in the BM group could not provide any benefit. Similarly, in a pooled analysis, Arda et al. [14] excluded Brucella meningitis from purulent meningitis. The DI scores of six Brucella meningitis patients were between -2 and 0 points, calculated with the resubstitution method. These scores were similar or close to the TM group as described: if the patient has a total DI score of 4 or less, he or she has TM. In clinical practice, this may lead to potential misclassification of Brucella meningitis cases in the TM group. In areas endemic for Brucella disease, this should be kept in mind.

Serum CRP levels have been the subject of several studies regarding the discrimination of bacterial and viral meningitis. Most of these studies were done on pediatric patients and very few included TM [15-17]. In an early study, Donald et al. [16] reported that CSF CRP levels in the BM group differed significantly from viral and TM groups. However, their study group was very small 
and comprised only 11 bacterial and 9 TM cases [16]. Sirijaichingkul et al. [18] reported significantly high serum CRP results in BM $(n=12)$ in Thai patients. Tuberculosis is still prevalent in developing countries and should be considered in the differential diagnosis of meningitis. Serum CRP probably should be added to the diagnostic indices for TM and BM.

In a meta-analysis, Gerdes et al. [19] reported that the CRP test discriminates well between patients with and without BM. However, the absence of analyses to show if CRP tests contributed independent diagnostic information relative to the information held in the traditionally used clinical and biochemical variables makes it difficult to evaluate the clinical usefulness of CRP tests in the management of patients suspected of having BM. The results of our study provide independent diagnostic information on the lack of knowledge on this point that was indicated by Gerdes et al. [19].
Serum procalcitonin is another protein that has been used in several studies on BM. However, it is an expensive method and using this parameter is not possible in most settings in developing countries.

The main limitation of the present study resides in its retrospective design and the small number of patients studied. However, most of the cases in both groups were confirmed microbiologically.

\section{Conclusions}

The findings of our study may provide important evidence for the utility of a DI in differentiating tuberculous from bacterial (except Brucella) meningitis by using simple and inexpensive clinical and laboratory parameters which can be applied easily in developing countries. Further research with prospective studies that include larger number of cases is necessary for validating this new DI.

\section{References}

1 Kumar R, Singh SN, Kohli N: A diagnostic rule for tuberculous meningitis. Arch Dis Child 1999;81:221-224.

$>2$ Hosoglu S, Ayaz C, Geyik MF, Kokoglu OF, Ceviz A: Tuberculous meningitis in adults: an eleven-year review. Int J Tuberc Lung Dis 1998;2:553-557.

>3 Fitch MT, van de Beek D: Emergency diagnosis and treatment of adult meningitis. Lancet Infect Dis 2007;7:191-200.

4 Michelow IC, Nicol M, Tiemessen C, Chezzi C, Pettifor JM: Value of cerebrospinal fluid leukocyte aggregation in distinguishing the causes of meningitis in children. Pediatr Infect Dis J 2000;19:66-72.

5 Sutlas PN, Unal A, Forta H, Senol S, Kirbas D: Tuberculous meningitis in adults: review of 61 cases. Infection 2003;31:387-391.

6 Refik Saydam Hygiene Center Presidency School of Public Health: The Ministry of Health of Turkey Health Statistics Yearbook 2009. Ankara, Republic of Turkey Ministry of Health, 2011.
7 Cagatay AA, Caliskan Y, Aksoz S, Gulec L, Kucukoglu S, Cagatay Y, Berk H, Ozsut H, Eraksoy H, Calangu S: Extrapulmonary tuberculosis in immunocompetent adults. Scand J Infect Dis 2004;36:799-806.

-8 Ozbay B, Uzun K: Extrapulmonary tuberculosis in high prevalence of tuberculosis and low prevalence of HIV. Clin Chest Med 2002; 23:351-354.

$\checkmark 9$ Maltezou HC, Spyridis P, Kafetzis DA: Extra-pulmonary tuberculosis in children. Arch Dis Child 2000;83:342-346.

10 Thwaites GE, Chau TT, Stepniewska K, Phu NH, Chuong LV, Sinh DX, White NJ, Parry CM, Farrar JJ: Diagnosis of adult tuberculous meningitis by use of clinical and laboratory features. Lancet 2002;360:1287-1292.

$\checkmark 11$ Brivet FG, Ducuing S, Jacobs F, Chary I, Pompier R, Prat D, Grigoriu BD, Nordmann P: Accuracy of clinical presentation for differentiating bacterial from viral meningitis in adults: a multivariate approach. Intensive Care Med 2005;31:1654-1660.

-12 Sunbul M, Atilla A, Esen S, Eroglu C, Leblebicioglu $\mathrm{H}$ : Thwaites' diagnostic scoring and the prediction of tuberculous meningitis. Med Princ Pract 2005; 14:151-154.

-13 Torok ME, Nghia HD, Chau TT, Mai NT, Thwaites GE, Stepniewska K, Farrar JJ: Validation of a diagnostic algorithm for adult tuberculous meningitis. Am J Trop Med Hyg 2007;77:555-559.
14 Arda B, Sipahi OR, Atalay S, Ulusoy S: Pooled analysis of 2,408 cases of acute adult purulent meningitis from Turkey. Med Princ Pract 2008; 17:76-79.

15 De Beer FC, Kirsten GF, Gie RP, Beyers N, Strachan AF: Value of $\mathrm{C}$ reactive protein measurement in tuberculous, bacterial, and viral meningitis. Arch Dis Child 1984;59: 653-656.

16 Donald PR, Strachan AF, Schoeman JF, De Beer FC: Cerebrospinal fluid C-reactive protein in infective meningitis in childhood. J Lab Clin Med 1985;106:424-427.

17 Vaidya AK, Wagle NM, Merchant SM: Use of CSF C-reactive protein in differentiating bacterial and non-bacterial meningitis. J Postgrad Med 1987;33:58-60.

18 Sirijaichingkul S, Tiamkao S, Sawanyawisuth $\mathrm{K}$, Chotmongkol V: C reactive protein for differentiating bacterial from aseptic meningitis in Thai patients. J Med Assoc Thai 2005;88:1251-1256.

19 Gerdes LU, Jorgensen PE, Nexo E, Wang P: $\mathrm{C}$-reactive protein and bacterial meningitis: a meta-analysis. Scand J Clin Lab Invest 1998;58:383-393. 